\title{
HISTORY \\ The Students' Health and Welfare Centres Organisation (SHAWCO) of the University of Cape Town: A review of the past 69 years
}

\author{
D M Favara, S C Mendelsohn
}

The Students' Health and Welfare Centres Organisation (SHAWCO) is a student-run non-profit community development organisation based at the University of Cape Town (UCT). In 2012 SHAWCO celebrates its 69th anniversary, making it the oldest active studentrun free clinic in South Africa. Over the past 7 decades, SHAWCO has become an integral part of UCT's Faculty of Health Sciences. This article reviews its history, current activities, and plans for the future.

\section{S Afr Med J 2012;102(6):400-402.}

The story of the Students' Health and Welfare Centres Organisation (SHAWCO) begins during the early 1940s, when industry allied to the Second World War effort attracted large numbers of indigent job-seekers to the Cape Town area. Most of these migrants settled in rapidly growing shanty towns on the outskirts of the city. Poor living conditions coupled with an absence of medical facilities allowed illhealth to flourish.

In December 1942 Andrew Kinnear, a UCT medical student, spent his vacation driving an ambulance to earn money to pay for his medical training. One of the places he visited was the shanty town of Kensington-Windermere where he was so appalled by the poverty, lack of hygiene and lack of medical facilities that he became determined to do something about it. When the new university term started in 1943, he began to explore the possibility of opening a clinic run by students. Kinnear asked Dr Golda Selzer of the Groote Schuur Hospital Pathology Department to help him to establish a clinic. Thus, in early July 1944, the 'Kensington Students' Clinic' was born, based at a local school in Kensington. In addition to providing healthcare, the medical students joined forces with the Union of Jewish Women (UJW) who began offering free lunches to the elderly at the clinic and started a crèche. Selzer, who remained involved with the clinic for many years, would later recall the efforts of the 'Kensington' students with great pride, lauding their 'organising ability, their idealism, their enthusiasm, efficiency and above all, their determination to give service to the people."

In March 1945, a second student-run clinic was opened in Retreat by medical student Pauline Urry. This was aligned with the Cape Flats Distress Association (CAFDA), an organisation established in the early 1940s concerned with the poor living conditions of the Cape Flats. The most significant development from this clinic was the establishment of mobile clinics using an ambulance, servicing areas far from the actual clinic sites. In April 1947, medical student Harry Currey opened the third student clinic located at the Retreat CAFDA

Dr D M Favara, currently an intern at the East London Hospital Complex, directed several SHAWCO clinics between 2006 and 2009. Mr S C Mendelsohn, a final-year medical student at the University of Cape Town, was President of SHAWCO in 2011.

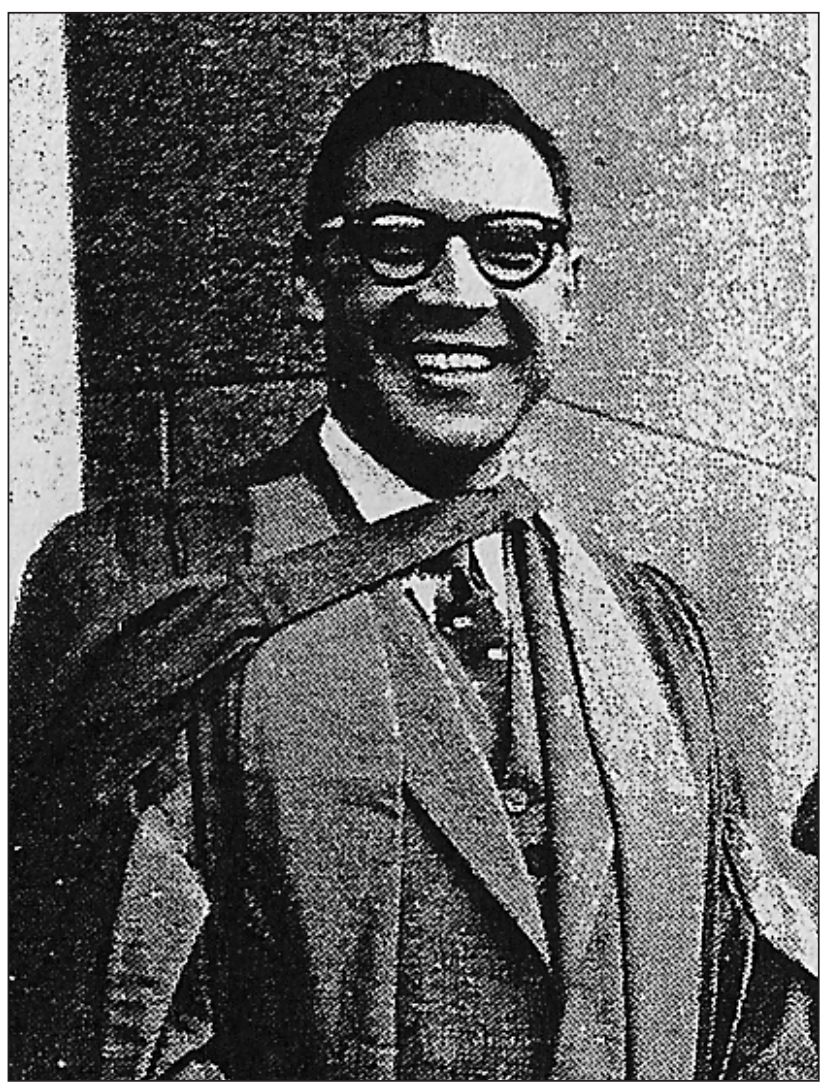

Dr Andrew Kinnear.

community centre. This later amalgamated with Urry's Retreat clinic. In 1950, the fourth student-run clinic was opened in Elsies River by medical student Harold Edelstein. These clinics would later form the backbone of the future SHAWCO.

In the early 1950s the Kensington Students' Clinic, CAFDA, and the UJW started a formal partnership. Land was bought in Windermere and a small clinic with an attached crèche was built. By this time, UCT was becoming increasingly interested in the student-run clinics. This led the Principal of UCT, Dr T B Davie, to give full support to the formation of a university-funded project 'incorporating health, welfare and educational activities conducted by the entire student body for those in need.' ${ }^{1}$ The function of this organisation would be threefold: (i) to continue and develop the student-run clinic service, (ii) to provide a student-run education service for the indigent, and (iii) to continue the welfare partnership 


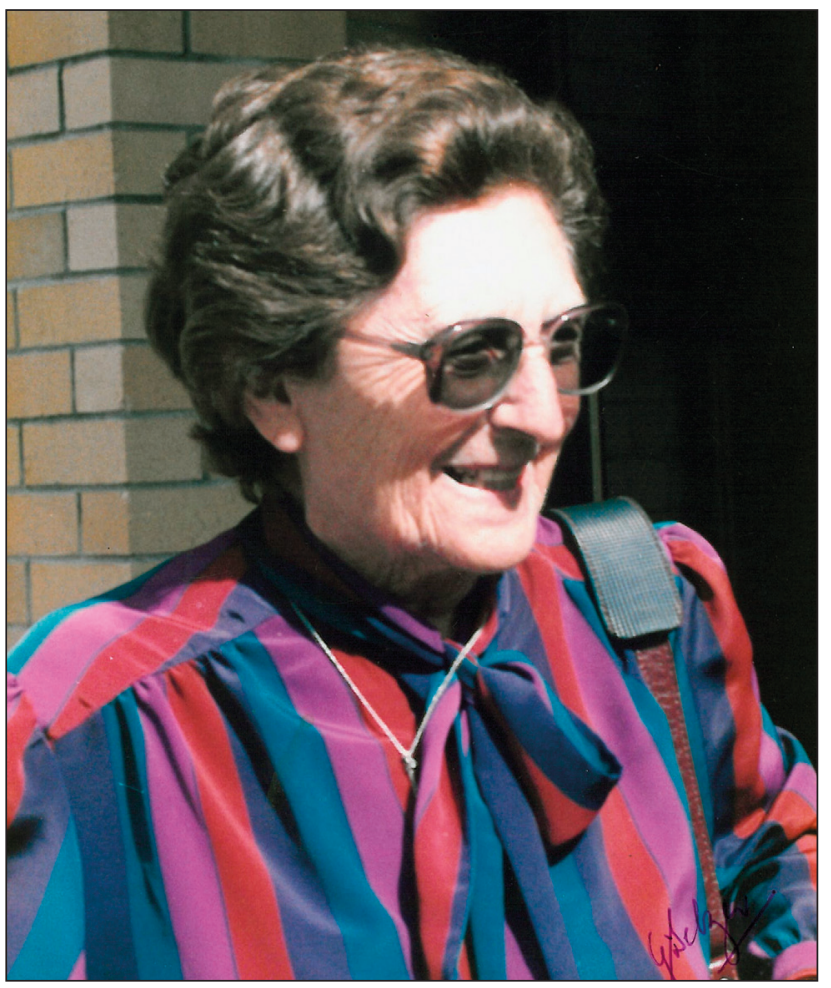

Dr Golda Selzer (1987).

with CAFDA and the UJW. Although originally named the Students Windermere Health and Social Centre (SWHSC), the new body was renamed The Students' Health and Welfare Centres Organisation (SHAWCO) and was formally approved by the University Council in 1954. In the same year SHAWCO registered as a welfare organisation.

The years that followed were filled with significant growth for SHAWCO. By the 1960s SHAWCO was operating 4 busy weekly clinics in Kensington, Retreat, Elsies River and on Prince George's Drive, as well as hosting a popular weekday night-school service. During the 1970s SHAWCO continued to expand steadily, moving its student-run clinics to areas of greater need, such as Langa and Crossroads, as well as increasing the scope of its education and welfare services. Attempts by the state to stifle its work only furthered its cause.

Since the late 1970s developments have included the building of the Manenberg centre, and introduction of new student-run clinics in Nyanga/New Crossroads and Khayelitsha. The waves of new studentrun clinics have tended to be followed by an increase in welfare and nutritional services. This is evidenced by the building of a nutritional and medical centre in Khayelitsha (K1) in 1985, the opening of a nutritional centre in Nyanga in collaboration with the UCT Child Health Unit, the opening of a community and educare centre in
Khayelitsha (K2/Sakhisizwe) in 1990, and a primary healthcare unit in Township 2, Khayelitsha (K3/Zibonele) in 1991.

In the mid-1990s, the newly elected democratic government took it upon itself to equitably provide social services to all citizens, marking the beginning of positive state intervention in the areas where SHAWCO functioned. SHAWCO thus felt that it was time to reassess its role. In December 1998, a decision was made to return to the state all the statutory social and welfare work that SHAWCO had gradually taken upon itself. Having made this decision, SHAWCO went through an extensive consultation process with its communities. As a result of these consultations, it was determined that (i) youth and issues relevant to youth, such as skills training, drug abuse, self-esteem, HIV/AIDS and unemployment, and (ii) the provision of care for the elderly and the disabled were the areas that the communities wanted SHAWCO to focus on. Healthcare projects, and the running of multipurpose community centres with skills training and recreation projects firmly remained part of SHAWCO's strategy. This transition marks the beginning of SHAWCO's emphasis on development, and only time will tell its impact on the communities SHAWCO serves.

\section{SHAWCO in the $21^{\text {st }}$ century}

Today, SHAWCO is divided into 3 sectors: education, health, and social enterprise. Both the health and education sectors are primarily student-volunteer driven, whereas the social enterprise is run by fulltime staff members.

The SHAWCO education sector focuses on community development through tutoring programmes for school learners and young adults in disadvantaged areas. The sessions cover a range of high school subjects, as well as extracurricular arts and sports activities. Currently there are 11 such projects, reaching over 1500 community participants through the efforts of around 800 volunteer students, predominantly from other (non-health-science) faculties.

Prior to 2003, SHAWCO was entirely dependent on donor funding. Faced with a financial crisis, the organisation took a decision to find alternative funding sources. This saw the creation of the SHAWCO social enterprise sector under the guidance of the then newly appointed Director of SHAWCO, Varkey George. All revenue generated through social enterprise projects is directly reinvested into the communities SHAWCO serves. Today, over half of SHAWCO's income is self-generated through such enterprises.

After all these years, the health sector still aims to fill the gap in primary healthcare service delivery in the Cape Town metropolitan area. It relies on volunteer doctors and health-science students in all years of study to ensure that free primary healthcare clinics operate in under-resourced and under-served communities throughout Cape Town. Annually, over 5000 patients are seen per year by over 800 medical and allied health-science students at around 250 clinics (Table 1). SHAWCO co-ordinates six generalist clinics which operate at night on a weekly basis in various Cape Town communities, and

Table 1. SHAWCO clinic statistics

\begin{tabular}{|c|c|c|c|c|}
\hline Year & Clinics $(N)$ & Student volunteers $(N)$ & Student volunteer sessions $(N)$ & Patients $(N)$ \\
\hline 2011 & 251 & 800 (including $>200$ international volunteers) & 2600 & $5130+$ \\
\hline 2010 & 248 & 824 & 2515 & 5604 \\
\hline 2009 & 180 & 557 & 1970 & 4806 \\
\hline 2003 & 115 & \pm 150 & Not recorded & 2005 \\
\hline 1963 & 3 sites & $63 \%$ of all UCT medical students & Not recorded & 14716 \\
\hline
\end{tabular}




\section{Table 2. Current SHAWCO clinics}

Simthandile Clinic (Khayelitsha) - Monday

New Rest and Barcelona Clinic (Gugulethu) - Monday

Brown's Farm Clinic (Nyanga) - Tuesday

Masiphumelele Clinic (Noordhoek) - Tuesday

Joe Slovo Clinic (Milnerton) - Wednesday

Zibonele Clinic (Khayelitsha) - Wednesday

Imizamo Yethu Paediatric Clinic (Hout Bay) - Saturday

Du Noon Paediatric Clinic - Saturday

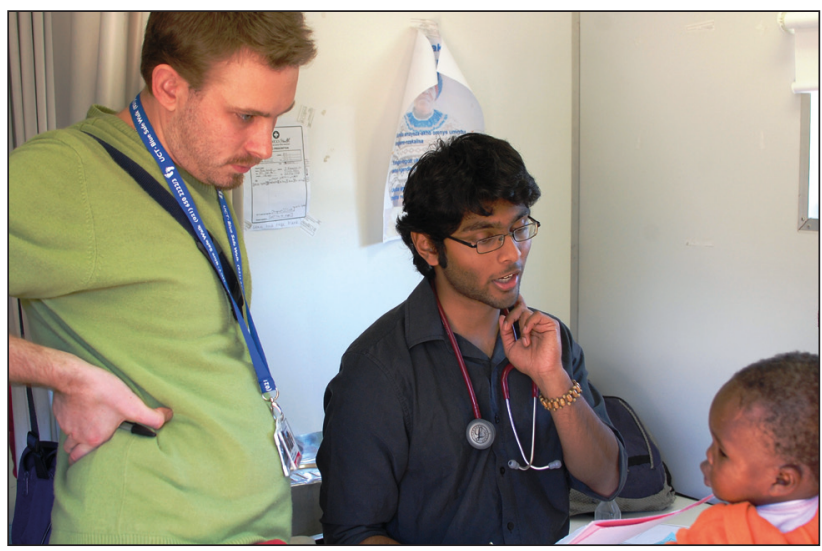

Medical students at work.

two Saturday morning paediatric screening clinics (Table 2). In 2009, SHAWCO introduced a weekly paediatric screening clinic, in partnership with the School of Child and Adolescent Health at UCT. These clinics often serve as the only port-of-call for community members who work during the day, or who cannot make the trip to the neighbouring day hospital/community health centre. The clinics either operate from permanent health facilities or from SHAWCO's purpose-built mobile clinics.

During clinics, patients are seen by medical students under the supervision of a qualified volunteer doctor who verifies diagnoses and provides clinical advice. Clinical students (in years $4-6$ ) are responsible for clerking, examination and treatment of the patients, while also guiding and teaching pre-clinical (years 1 - 3) students. This fulfils another major role of the clinics - providing education and experience to future doctors and instilling a passion for primary healthcare, a point made by Selzer, ${ }^{2}$ writing in this very journal 49 years ago, that the community-based approach enables students to appreciate aspects of medical practice which cannot be experienced within the academic hospital setting. The most common presentations to the SHAWCO clinics (in 2011) are listed in Table 3.
Table 3. Common presentations at SHAWCO clinics in 2011

\begin{tabular}{lll}
\hline Presentation & $\boldsymbol{N}$ & $\%$ \\
\hline Dermatological & 884 & 17.30 \\
Upper respiratory tract infections & 589 & 11.60 \\
Backache & 246 & 4.80 \\
Urinary tract infections & 201 & 3.94 \\
Acute gastroenteritis & 157 & 3.10
\end{tabular}

Writing in the British Journal of Medical Education in 1967, David $\mathrm{Katz}^{3}$ (then a fourth-year medical student) notes that the clinical environment of SHAWCO also 'enables the student to handle a patient with ease, enhancing the doctor-patient relationship' In some ways this article was well ahead of its time, advocating the benefits of holistic biopsychosocial medicine: 'The student sees the patient as a whole, as a sick human being, and simultaneously has the opportunity of seeing the environment which surrounds the sick human being.'3

Anecdotal evidence suggests that students who volunteer for SHAWCO clinics are better prepared to deal with the rigours of their internship and community service years, but this has not been formally investigated.

\section{The future}

Despite the hopes of many people post 1994, and the promises of the new government, there remains a gaping crevasse in healthcare service delivery in Cape Town and the need for student-run free clinics remains. The same can be said of education. The SHAWCO health sector is now investigating the feasibility of implementing a more holistic 'preventative' primary healthcare model, as well as capacity building, to replace its current primarily 'curative' healthcare model. The implementation and results of this transition will be of great interest.

\section{Conclusion}

For the last 69 years, SHAWO has been at the fore of aiding impoverished communities within the Cape Town area. This is testament to the collective hard work, dedication and passion of its students, staff and supporters, past and present. Here's to the next 69 years!

For more information: http://www.shawco.org, email: info@shawco.org and health@shawco.org.

\footnotetext{
1. Van Heyningen E. The history of SHAWCO, 1943-1975. Cape Town: Students' Health and Welfare Centres Organisation, 1975

2. Selzer G, Gordon H. SHAWCO: the Students' Health and Welfare Centres Organisation of the University of Cape Town. SAMJ 1963;37:58-59.

3. Katz D. The Students' Health and Welfare Centre (SHAWCO), University of Cape Town, South Africa. British Journal of Medical Education 1967;1(3):178-182.
}

Accepted 6 February 2012

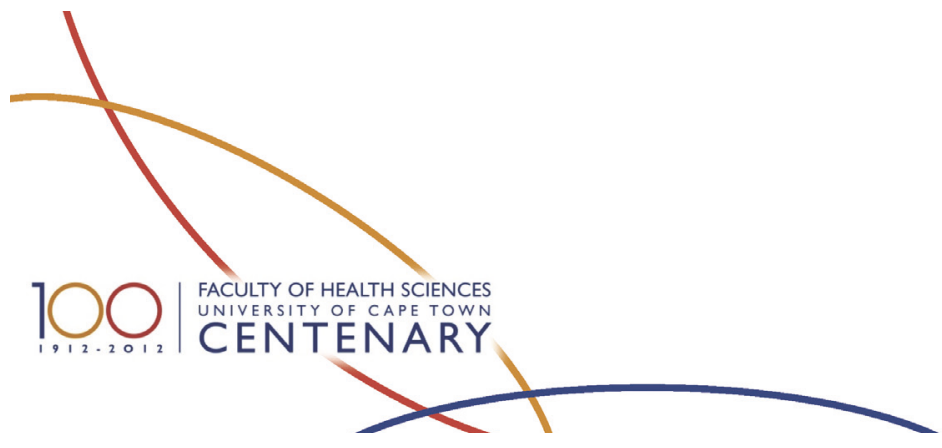

